\title{
La política de los afectos en La resta de Alia Trabucco Zerán: corporalidades en el límite de las clases sociales*
}

\author{
The Politics of Affects in La Resta by Alia Trabucco Zeran: \\ Corporealities at the Limits of Social Classes
}

Constanza Ternicier Espinosa**

\begin{abstract}
RESUMEN
La resta (2015) de Alia Trabucco Zerán (Santiago de Chile, 1983) puede ser leída a partir de una tensión de clase que es movilizada por medio de determinados tonos afectivos inscritos en los cuerpos de sus protagonistas. Trabucco nos propone una dialéctica entre los personajes de Felipe e Iquela a través de dos dimensiones que los confrontan desde una política de los afectos. En primer lugar, su corporalidad, que posee un carácter móvil, abierto y fusionado con la escritura y, en segundo término, la problemática de clase que determina sus derroteros. Es a través de esta fricción que se produce el juego de una resta que suma, o bien, de una suma que resta: operaciones dialógicas que permiten procesar el peso de la historia y de la muerte.
\end{abstract}

Palabras clave: nueva narrativa chilena, política de los afectos, clase social, corporalidades, posdictadura.

\footnotetext{
* Este trabajo es uno de los resultados de mi tesis doctoral sobre literatura chilena reciente. Realizada en cotutela entre la Universidad Autónoma de Barcelona y la Pontificia Universidad Católica de Chile, recibió por parte de esta última el Premio a Excelencia en Tesis Doctoral en el área de Humanidades el 2018. La tesis "Dos sistemas de preferencia en la narrativa chilena reciente: exhortar al campo literario del 2006 en adelante", como su título lo sugiere, tuvo una finalidad cartográfica de recoger las obras narrativas de un corpus paritario de 16 autoras y autores nacidos entre 1978 y 1990, y que comenzaron a publicar desde la fecha señalada, considerada un hito fundacional por varias razones: la muerte de Augusto Pinochet; el levantamiento de los llamados "pingüinos", quienes inician fuertes presiones desde su formación secundaria para promover una reforma en la educación; y el triunfo del primer mandato de Michelle Bachelet. Esto coincide con un boom de editoriales que no sin cierta falacia reciben el nombre de independientes y que comienzan a dar acogida a narradores cuyas luchas de campo tienden a ignorar figuras parentales para más bien ubicarse desde lazos que son horizontales. Trabucco coincide con muchas de estas subjetividades, pero es sin embargo una excepción en lo que refiere a esta exclusiva horizontalidad. Sus genealogías quedan tendidas con autoras como Lina Meruane (1970) y Nona Fernández (1971).

** Profesora Asistente Núcleo de Formación General, Facultad de Estudios Interdisciplinarios Universidad Mayor. constanza.ternicier@umayor.cl
} 


\begin{abstract}
La resta by Alia Trabucco Zerán (Santiago de Chile, 1983) reads from a class tension that mobilizes using certain affective tones inscribed in its protagonists' bodies. Trabucco advances a dialectic between Felipe and Iquela, which will occur between two dimensions that confront them and engage them in dialogue, based on a politics of emotions. Firstly, their corporealities, which will always have a mobile attribute, opened and merged with writing. Secondly, a social class problem that determines its courses. This friction thus produces a scheme of adding subtraction or subtracting sum: dialogical operations that will process the weight of history and death.
\end{abstract}

Keywords:New Chilean Narrative, Politics of Affects, Social Class, Corporealities, Post-dictatorship. 


\section{Estado de la cuestión: una literatura de los hijos}

La resta (2015) de Alia Trabucco Zerán (2015) plantea la impugnación de los hijos frente a aquellos padres militantes que participaron activamente contra la dictadura de Augusto Pinochet, lo cual ciertamente constituye una novedad en una configuración genealógica donde los hijos solían ser espectadores de la frustración arrastrada por padres que vieron cómo fracasaba su proyecto político ${ }^{1}$. Ahora bien, y pese a que el presente artículo no se centrará en ello, resulta relevante trazar este antecedente como un estado de la cuestión y como una de las lectura posibles de la obra.

Recientemente, Trabucco Zerán publicó bajo el formato de un ensayo literario los resultados de su tesis doctoral que conllevó un minucioso trabajo de archivo sobre los expedientes de cuatro casos de mujeres asesinas a lo largo del siglo XX. En Las homicidas, publicado a principios del 2019 por Lumen, la autora fusiona la ficción con notas de prensa, decretos jurídicos y los rastros de su propia búsqueda en una investigación que no deja a nadie indiferente. Nuevamente, disloca el lugar común. Así como en La resta saca a los hijos de la dictadura del lugar de víctimas pasivas, en Las homicidas saca a las mujeres de la posición histórica de asesinadas para situarlas en la de asesinas, contrariando las convenciones del género.

La llamada literatura de los hijos fue sin duda un instrumento de análisis crítico que pareció calzar con los lectores ideales concebidos por la generación anterior a la de Trabucco, es decir, la de aquellos autores nacidos en los 70 y que comenzaron forjando su trayectoria

1 En La resta de Trabucco se produce una tensión entre padre e hijos. La autora deja traslucir una posición de secundaridad que es transversal a los tres jóvenes protagónicos y que se relaciona con su minoría de edad y su condición de hijos de padres militantes, dos de ellos muertos: el de Felipe, tras ser delatado torpemente por los padres de Paloma e Iquela; y la madre de Paloma, quien padece un cáncer durante su exilio en Alemania y cuyo cuerpo es repatriado para darle sepultura en su país de origen. Será Felipe el más consciente de tal posición: "se sienten protagonistas sin entender que no son protagonistas de nada, aquí somos tramoyeros todos, gringa, ni pa' personajes secundarios nos da" (128). La sensación de falta de pertenencia, de un arraigo propio, es un conocimiento o anagnórisis que Iquela procesa hacia el final de la novela cuando al fin arriban a Mendoza: "Ninguno de esos aviones había podido aterrizar en Chile. Ni siquiera esa tragedia (su catástrofe, su funeral, me repetí), ni siquiera eso nos pertenecía” (244). En este sentido, se subraya aquí una falta que no solo tiene que ver con la dificultad de reconstruir la memoria, sino también por el hecho de sentirse al margen de una lucha y una historia que ellos, los hijos, no logran asimilar totalmente. 
literaria cuando aún no se producía la descentralización que arrastraría consigo el boom de editoriales independientes, para las cuales las relaciones entre los subsistemas del campo se fueron volviendo progresivamente más horizontales. Autores como Alejandro Zambra, Álvaro Bisama, Nona Fernández y Alejandra Costamagna pueden ser ubicados aquí. Lorena Amaro (2014) pone el énfasis en estas escrituras que han hecho de la infancia un locus de la memoria, vinculado con aquello que Dominique Viart (2009) llama "relatos de filiación" (96), donde los narradores buscarían conocer y a la vez cuestionar su herencia. Según Ignacio Álvarez (2013), Mouat, Bisama y Zambra son algunos de los autores de esta generación previa que experimentan una gran determinación por parte de las figuras parentales: "En todas estas novelas los niños valoran y aprecian a sus padres, están inevitablemente determinados por ellos o emprenden su búsqueda y logran encontrarlos. En el antiguo idioma de la antropología estructural, diríamos que la paternidad aparece "sobrevalorada" en estas novelas, pues es atesorada en su valor o padecida con intensidad" (s/p). Más aun, considera que esta generación manifestaría una resistencia por la vida adulta y por asumir el proceso de crecer. Claudican ante la posibilidad de escribir la historia, pues están sobredeterminados por los relatos de los padres. Ciertamente, este problema entre padres e hijos pasa a ser político².

Para Jeftanovic (2011), quien también forma parte de la generación descrita, las narrativas de la infancia funcionan como una estrategia que permite desplegar procesos de subjetivación empujando al lenguaje y al imaginario a límites y zonas insospechadas. La tensión que viven los niños respecto del futuro opera como un significante abierto. Los niños y adolescentes se constituyen, según la autora, como sujetos subalternos que están al margen del poder y del conocimiento especializado. Aquel uso estratégico y testimonial, que en primera persona se realiza desde una pequeña voz, sirve para cuestionar los discursos dominantes ubicados en el centro. El lugar "des-

2 Para Deleuze y Guattari (2001), son conflictos que adquieren un valor colectivo y que buscan representar la voz de una minoría: "La posibilidad de debate de la oposición entre padres e hijos no se trata de un fantasma edípico, sino de un programa político" (29). La juventud y la condición de hijos pasa a ser el espacio de una literatura menor. Se apuesta por una estética de lo privado o intrahistórico y que opera a través de relatos que versan de micropolíticas más bien familiares e íntimas. 
aventajado" del niño, que es vulnerable y no se puede explicar algunas cosas, es utilizado por los autores para inscribir sus resistencias. Desde la perspectiva de Lina Meruane (2015), en tanto, este malestar de los hijos ha impuesto una tiranía de la que es necesario liberarse. Ahora bien, Meruane - con quien Trabucco traza evidentes afinidades electivas-, observa esta queja a partir de su posición de potencial madre que se niega a dicho mandato social donde la maternidad es puesta al centro de la familia (su razón de ser). Ello generaría posiciones culpógenas en los padres, quienes estarían constantemente martirizándose por sus hijos; dispuestos en un lugar sagrado en que, como la misma Jeftanovic señalara, "se miran pero no se tocan" (130). Bajo el supuesto de que los conceptos de infancia y adolescencia han sido inventos tardíos dentro de la sociedad, Meruane considera que en el último tiempo además se ha favorecido el "surgimientos de una raza de hijos-estorbo, de hijos-mimados, de hijos-caprichosos, de hijos-irresponsables y rabieteros o, peor, de hijos-abusadores y hasta maltratadores: sobre todo de sus madres" (131).

Ana Eva Rodríguez (2016) publica una reseña acerca de La resta donde pone el acento en la desviación de la realidad que opera desde los padres hacia los hijos, como si de algún modo estos últimos se vieran obligados a trasladarse de un lugar a otro que no terminan de comprender del todo y ello les supusiera una serie de desajustes: "El desfase con esta realidad otra, que se presenta como un nuevo acontecer en un tiempo pasado, impide adaptarse a un orden distinto de los hechos" (474). Por lo demás, la autora inscribe la obra de Trabucco como si estuviese en continuidad con la llamada "literatura de los hijos" que marcaría la narrativa de posmemoria y posdictadura en Chile, en tanto "el relato se entreteje a través de un diálogo constante entre la memoria de los padres que se adhiere - casi inevitablemente- a la generación de los hijos; quienes fueron forjando su sentir y sus estructurales mentales en torno a un pasado fuerte del que jamás serían protagonistas, sino meros marginados de la historia" (474). Rodríguez percibe un solapamiento dentro del cual se vuelve muy difícil distinguir dónde termina un relato y comienza el siguiente.

Luego, en la presentación de la edición chilena de la novela, a cargo de la editorial Tajamar, la escritora Alejandra Costamagna (2016), 
una de las voces que precisamente ocupa el lugar de esa literatura de los hijos, subraya una operación aritmética que se produce en el orden de la palabra: "Porque esta es una novela sobre muertos-vivos, como vemos desde el inicio, pero también sobre las palabras para dar cuenta del pasado de estos muertos en el presente de los vivos" (210). Costamagna, quien dirigiera alguno de los talleres tomados por Trabucco y con quien entreteje evidentes genealogías de afiliación, tras la presentación y en su reseña para Taller de Letras, pone el énfasis en la transmisión de una herencia política, pero ya no desde un punto de vista pasivo, sino como conductores de un viaje donde ellos son los protagonistas y deciden el destino de sus muertos.

\section{Escritoras tránsfugas}

Alia Trabucco se inscribe en aquellas escrituras que, dentro de la categorización realizada en mi tesis doctoral, llamo tránsfugas. En mi investigación se propusieron cuatro categorías dentro de las cuales fue posible identificar y agrupar a los autores del corpus sin perjuicio de la movilidad que ellos poseen para desplazarse a través de las mismas. Parto del entendido de la dificultad que supone referirse a los sujetos de un modo unitario y, más aun, desprender de ellos una identidad. Pese a lo anterior, hay cuatro subjetividades que responden a diferentes modos de enunciarse y donde jugarán un rol clave los siguientes aspectos: el género, la clase social y la disposición epistemológica frente a la historia y el entorno. La conjunción de estos tres factores da el siguiente resultado: 1. mujeres tránsfugas; 2. escritores estoicos; 3. escritores del margen, dentro de los cuales hallaremos tanto los arrabales de la provincia como la marginalidad recreada por los cínicos; y 4 . la taciturna clase media. En esta sistematización se toma prestada una clasificación propuesta Ignacio Álvarez (2012), quien propone tres intenciones en la narrativa del noventa y el dos mil; las cuales podrían vincularse a tres sensibilidades propias del mundo helenístico. Según la relación epistemológica que los sujetos establezcan con el mundo material, podría rastrearse el siguiente panorama: mientras los textos estoicos anhelan melancólicamente un contacto con las cosas pasadas que han perdido; los escépticos no creen en ello y sostienen una actitud crítica con el presente; $y$, finalmente, los epicúreos, incapaces de distinguir entre percepción e imaginación, exasperan la propia producción simbólica 
como una manera de reinventarse el futuro. La epistemología posee, en tal sentido, un sentido ético. Para Patricio Marchant (2000), la episteme no determina la verdadero, pero "fija, sin embargo, un nivel de responsabilidad" (433). Las escritoras tránsfugas poseen ese ímpetu epícureo que se permite recrear e imaginar una nueva realidad: una apuesta que, en efecto, es sostenida por las vertientes más optimistas del feminismo (Braidotti, 2000).

Se trata de autoras posicionadas en un borde del orden simbólico, desde donde adquirirán las propiedades desconcertantes de todas las fronteras: no están ni en un lado ni en el otro, son transfronterizas. Optan por lo tránsfugo, por el desvío permanente, por la fuga. Esto será determinante en aquellas novelas de formación cuyo acento está puesto en el momento de tránsito de entrada a la sociedad y su universo simbólico, en tanto ponen en escena subjetividades que no acatarán los lugares tradicionales que la sociedad dispone para ellas. Son narradoras que descomponen ese horizonte desde una semiótica y un uso poético de los signos que acaba cuestionando un orden realista de las cosas, precisamente porque bajo los códigos del realismo el peaje a pagar sería muy alto: implica adecuarse a los valores identitarios de la nación con sus binarismos de clase y género. Sus escrituras optarán por un lenguaje que imagina otras posibilidades de lo real, por tanto, el uso de la alegoría u otras formas figurativas aparecerá con frecuencia en sus obras.

La imagen de lo tránsfugo alude, a su vez, a un movimiento constante que no soporta la quietud. Son escrituras inquietas, donde el tópico del viaje será visitado en sus variadas posibilidades. Asimismo, hay una relación entre estas formas de escritura nómade y la denominada literatura transreal ${ }^{3}$. La nomadía puede ser comprendida en consonancia con ese transrealismo que se fija en los puntos de fricción y las zonas liminares antes que en los espacio o sujetos de identidad monolítica.

3 Lo transreal no solo pretende ir más allá de las fronteras de la nación, sino que pone el acento, según señala Julio Ortega (2012) citando a Ottmar Ette, en los trayectos, el diálogo y los bordes. En síntesis, acoge los caminos antes que los territorios. Como indico en mi artículo "Los conflictos de una literatura nacional: raíces y desarraigos" (2018), este concepto ayuda a desestructurar las rígidas nociones de centro y periferia, además de permitirnos entender que lo nacional y lo posnacional no pueden ser planteados en términos maniqueos y como si lo segundo fuera la superación de lo primero. 
Es así como las escritoras tránsfugas se identifican con aquellas sujetas nómades de Braidotti (2009), quienes tienden puentes, interconexiones y transiciones de la vida; un aspecto que, por lo demás, no puede desvincularse de su "deseo de pensar a través del cuerpo y no en una huida del mismo" (18).

El interés por escapar de lo nacional y fugarse - muy presente en nuestras narradoras mujeres, cuya necesidad de desarraigo y huida del suelo nacional parece más imperante- encuentra en la historia de La resta un asidero histórico, a saber: la experiencia del exilio. Se expone aquel conflicto entre lo que significa quedarse o irse del país: la historia de Iquela o la historia de Paloma. La cordillera se vuelve aquel espacio infranqueable que será el escenario principal de esta suerte de road movie mortuoria. El afán por escapar y salir de la casa materna es también un intento por hacerse de una historia propia que resignifique los acontecimientos poco certeros de la memoria: "Yo planeaba ese viaje como se planifica una fuga. Salir. Salir de Santiago a toda costa. Tenía ahorros suficientes para alejarme unos kilómetros en cualquier dirección, aunque la única dirección que había tomado mi vida había sido a ocho cuadras y media de la casa de mi madre" (Trabucco 40). Es, además, el afán de escapar de la casa burguesa y de los mandatos de la familia para iniciar trayectos que, en definitiva, logran liberar al sujeto de sus determinismos afectivos. La importancia de la fuga en estas narradoras tendrá también asidero en los lugares de inscripción de sus autorías: entre Londres, Santiago de Chile y Estados Unidos en el caso de Alia Trabucco, quien encontró en la Universidad de Nueva York un espacio de legitimación junto a Lina Meruane y al amparo de una voz tan importante como Diamela Eltit.

\section{Dos criterios de análisis: género y clase}

En La resta, Paloma, Iquela y Felipe emprenden un viaje mortuorio para dar con el cadáver de la madre de Paloma e iniciar así sus ritos fúnebres. Así será cómo estos tres personajes comenzarán a activar un proceso de resignificación del pasado y con ello instalarán un mapa afectivo particular en torno al cruce entre la corporalidad y la clase social. El giro afectivo busca desmantelar las jerarquías epistemológicas que organizan la dicotomía entre las emociones y la razón, 
muy ligada al cuestionable binarismo de lo femenino y lo masculino, con el fin de revertir aquella clásica desvalorización de los afectos como si se tratasen de meros estados psicológicos. Sara Ahmed, en su libro La promesa de la felicidad. Una crítica cultural al imperativo de la alegría (2019), utiliza el concepto de "economías afectivas" que por medio de un tráfico emocional regularían nuestra relación con el entorno. Según señala Nicolás Cuello en el prólogo a la edición argentina de este texto, "propone así un modelo de sociabilidad emotiva que se sobrepone a las determinaciones de análisis individual y las generalizaciones superestructurales, para dar cuenta del funcionamiento de las emociones como políticas culturales geopolíticamente situadas" (14).

El primer criterio, a saber, el género, ha de ser problematizado y entendido desde la perspectiva de Judith Butler. En El género en disputa: el feminismo y la subversión de la identidad (2007), la autora se manifiesta en contra de categorizaciones rígidas sobre la identidad de los sujetos; específicamente aquellos planteamientos que presuponen los límites y la corrección del género, en cuanto restringen su significado a las concepciones generalmente aceptadas de masculinidad y feminidad. Ahora bien, su propuesta deconstructiva no se plantea desde una mera aplicación del posestructuralismo, sino que responde a una teoría de reformulación específicamente feminista. Butler se centra en cuestionar la estabilidad del género como categoría de análisis, puesto que ha emergido como la forma rígida de la sexualización de la desigualdad entre hombres y mujeres. Desde ese punto de vista, por ejemplo, el lesbianismo - sugerido en la obra de Trabucco- no supone un afán por recuperar la importancia de ser mujer o de consagrar la feminidad dentro de un mundo ginocrítico, sino de salirse de la vigilancia del género y de un punto de vista que, en última instancia, siempre trasunta una heterogeneidad normativa. En ese sentido, Trabucco deconstruye la dicotomía del género a través de sus complejos personajes.

En segundo lugar, aparece la clase como un criterio que, dentro de las lecturas críticas que ha tenido la obra, no parece llamar demasiado la atención. Pese a que bajo la lógica de un paradigma sistémico que anima el estudio de la circulación de nuevas narrativas - como las de Alia Trabucco- en el medio cultural, la sociedad es comprendi- 
da como parte de una serie de subsistemas que rondan sus órbitas de manera independiente, como si se trata de un universo acéntrico; es bastante evidente en un estadio de capitalismo tardío que el sistema económico, a pesar de su supuesta mano invisible, sigue ocupando un lugar preponderante y central. Por ello, consideramos urgente instalar el problema de la clase al centro de cualquier esfuerzo por cartografiar nuevas subjetividades presentes en el campo literario.

Ahora bien, referirse a las clases sociales constituye en sí un problema, porque normalmente, y como aclara Richard Hoggart en The uses of literacy: Aspects of working class life (1957), la pertenencia a una clase queda definida por las miserias y las mezquindades que supone. No se adscribe a ella desde la exaltación de la misma, sino más bien a partir del conflicto. Trabucco no saca a relucir las características de dos clases diferentes para glorificarlas o impugnarlas por sus vilezas, sino que simplemente las confronta y las tensiona en sus materialidades discursivas. Contrapone así dos voces que se debaten en sus modos de asimilar el pasado y las muertes que dejó consigo una dictadura de nefastas consecuencias.

\section{Afecto y las deconstrucciones del género}

Trabucco invierte los convencionalismos del género al presentarnos una voz contenida a través del personaje de Iquela y una desbordada en Felipe, quien por lo demás viene a ocupar el rol de Antígona: figura mítica que subyace en La resta, en tanto todo el esfuerzo de los tres amigos tiene su telos en la realización de unas pompas funerarias que permitan el trabajo de duelo. Dentro de las masculinidades trabajadas en la obra, llama la atención que los personajes construidos desde un punto de vista más tradicional no cumplan un modelo satisfactorio: desde figuras ausentes como Hans, el desaparecido padre de Paloma; pasando por hombres opacados por la omnipresencia de la mujer, como es el caso de Rodolfo, padre de Iquela; hasta progenitores muertos como los de Felipe, delatados torpemente por Hans y Rodolfo. Felipe, sin embargo, se rebela frente a este modelo y nos propone una alternativa. De hecho, él se opone al orden patriarcal y, según lo indicado por Edmundo Paz Soldán (Providinci, 2016), podría considerársele una versión contemporánea de Antígona, la heroína del mito griego dispuesta a enfrentarse a la ley en procura de dar los 
ritos fúnebres adecuados a su hermano Polínices ${ }^{4}$. Felipe representa a esa Antígona que defiende, en vez del derecho a un entierro, una ley propia para poder dar cuenta de la muerte. Propone una matemática espiritual engarzada con el orden de los sentimientos y la necesidad de cerrar determinados círculos rituales que podrán irse concretando desde la escritura y su voz poética.

La sexualidad de Felipe es ambigua. Puede coquetear con Iquela, en una relación casi incestuosa, o con Paloma. Más bien, le gusta ser el espectador del reencuentro erótico entre las dos chicas que se conocen el día del Plebiscito: "métale corriéndose mano las dos frescas, compensando la pena con besucones" (177). Pese a la cercana relación de Felipe con Iquela y a sus juegos infantiles, nunca persistieron ellos en un vínculo sexual. Parecen indolentes incluso al deseo: "si nosotros habíamos acordado que seríamos choznos o que ella sería mi papá y yo su hija, pero pololos nunca, ¡claro que no!, si ni ganas nos dieron de seguir tocándonos, porque ni curiosidad fisiológica teníamos de cabros chicos, nacimos con el lóbulo de la sorpresa extirpado nosotros, si ni las cenizas nos sorprenden" (180). A partir de aquí, se pone en marcha un procedimiento grotesco para referirse al sexo como desde un colectivo, esto es, desde la animalidad que pueda suponer. Felipe se siente atraído por la imagen de Iquela y Paloma dentro del auto, aunque apenas puede ver a través de los vidrios empañados: "no veo más que las siluetas, los contornos de esos cuerpos que se arriman, unos gatitos huérfanos que se reconocen y se lamen [...] me calienta aunque la Iquela sea como mi hermana, mi chozna, mi papá, me caliento

4 En "De la facultad de ver al derecho de mirar", Victoris Sau (2000) se refiere a Antígona como un ejemplo de la última vez que una mujer habló a un hombre cara a cara, de igual a igual. Hija de Iocasta y Edipo, se enfrenta a Creonte, su tío materno, que la pretende condenar a ser enterrada viva. Con él discutirá variados temas como las contradicciones entre la vida y la muerte, lo humano y lo divino, la diferencia entre los sexos, la familia y la ciudad. Luego, se quita la vida antes de que se ejecute la sentencia. Su suicidio enfatiza un doble gesto subversivo de desobediencia frente a una ley del Estado y la razón puesta por encima del orden de los sentimientos. Analiza el enfrentamiento entre Antígona y Creonte. De tal modo, opone los lazos de sangre a la ley de la polis, las exigencias del afecto familiar y las normas racionales. Desde una perspectiva que Sau acusa de patriarcal, el filósofo asocia lo universal a Creonte. Allí tendría cabida la singularidad del placer y el goce, además de la actividad real. En el rey de Tebas se fundiría carne y espíritu, mientras que en Antígona estaría representada la petulancia de la juventud sin madurez. Tales juicios sexistas son desbarajustados en la novela de Trabucco. 
porque son cuerpos animales, cuerpos que se dan calor porque están solos, eso pienso y se me aparece mi perrito-hermano" (180-181).

En definitiva, los afectos y las corporalidades donde estos se expresan están siempre en función de este juego de relaciones duales entre una pareja y un tercero excluido: "Los cuerpos adoptan la forma del contacto que tienen con los objetos y con los otros" (Ahmed, La política cultural... 19). Para Bourdieu (1979), el cuerpo siempre está socializado "mediante la familiarización con un mundo físico estructurado simbólicamente y a través de la experiencia precoz y prolongada de interacciones caracterizadas por las estructuras de dominación” (202). Esto nos permite rescatar la pregunta de Ahmed: “ ¿qué cuerpos temen a qué cuerpos?" (114). Aquí Felipe teme a Iquela y a Paloma, a pesar de ser supuestamente él quien ocupa una posición dominante. Trabucco invierte dicha relación en cuanto al género.

Trabucco propone un juego de afectos que cuestiona las relaciones habituales entre los géneros al cruzar lo emotivo con lo histórico. Mabel Moraña e Ignacio Sánchez (2012) arguyen que en el caso de América Latina la exploración del tema del afecto ha tenido lugar a través del estudio de sus formas de manifestación y representación artística, con anterioridad al impacto del "giro afectivo" que comenzó a posicionarse en la academia norteamericana a mediados de los 90, desde varios campos de investigación transdisciplinarios, como los programas de estudios de mujeres, los estudios queer y los estudios culturales. El estudio del nivel emocional se ha dado en general estrechamente asociado con el nivel ideológico (322), por tanto, no refiere a afectividades individuales y aisladas de su contexto, sino que cargadas por el peso de la historia: algo visible e inevitable en la novela La resta.

La novela alude al acto sexual y la delicia del otro desde una íntima relación abstracta donde el cuerpo se funde con la escritura y donde los sujetos son tratados como animales tiernos. Así será ilustrado desde la perspectiva de Felipe quien, pese a formar parte de una relación triangular, queda fuera de este juego. No obstante, esta triangulación que parece dejar a un tercer excluido es operativa y les permite mantener el vínculo. A pesar de una orfandad de relatos y referentes claros, ellos forjan una comunión visceral del cuerpo y el afecto que actúa como una "zona de contacto" (Ahmed 292) cuyo objetivo pareciera ser 
darles a los tres jóvenes la posibilidad de crear un relato de lo vivido. Es de hecho ese vector afectivo el que les permite rememorar y darle un significado al pasado.

Ahora bien, Felipe parece más entregado que las chicas a diversas pulsiones homoeróticas en su peregrinar por la ciudad. Incluso más: el mismo territorio urbano es comprendido como una corporalidad en tanto parece existir una metonimia entre su geografía y los deseos de Felipe, quien nos dice que "la cuenca del río está enterrada en mi piel, en la línea de la palma de mi mano, el cauce de mi sangre atraviesa la ciudad, esta ciudad que es mi cuerpo" (278). Lucía Guerra es ilustrativa en ese sentido cuando nos dice que los homosexuales hombres ocupan un afuera urbano - en tanto lugar de autoexploración erótica-en el que las mujeres lesbianas aún no se posicionan: "Si la sexualidad / identidad lesbiana es lo oculto que se manifiesta (mantiene) generalmente en espacios privados, el secreto de la homosexualidad masculina transita por las calles de la ciudad creando cartografías del deseo que transgreden y contradicen los significados asignados a cada lugar por la nación heterosexual y una economía de consumo dirigida a la familia" (227). La búsqueda sexual de Felipe está anclada a esos parajes fríos y desolados que bordean al río Mapocho, por ejemplo, donde un vagabundo le practica sexo oral:

¿querís que te lo chupe, pendejito?, y yo no sé, pero le digo que no, porque cuando no sé algo digo que no, así siempre sé, y él se ríe y pregunta si acaso me da miedo, si te gusta no significa que seai fleto, pendejo rico, aunque yo soy una loca, una maraca, una yegua cualquiera, y se ríe más fuerte y se acerca y me sorprende el peso de su mano en mi entrepierna y la mano es delgada y huesuda y entra por mi calzoncillo y siento que me saca el pico del pantalón, sí, lo saca y lo sacude y en un segundo se me pone duro, y me agarro de la baranda para así pensar en cosas frías como el hielo, el río, el metal [...] y mi boca está seca, mis ojos secos, el río seco y el fuego en su mano se apaga y caen los restos al Mapocho. (108)

Es interesante observar cómo lo erótico convive con lo tanático a lo largo de toda la novela. Ambos impulsos se complementan configurando un dualismo y no una dualidad contradictoria. Tal fuerza destructora anuncia un apocalipsis que, sin embargo, no llega ni se concreta nunca. La amenaza de las cenizas que caen sobre la ciudad se mantiene 
suspendida, como tal, en tanto amenaza, como profecía, como deseo: “(Pero nada arde. Nada se derrumba. Nada se calcina)" (111).

\section{Las sumas y restas de las clases sociales}

El elemento alegórico anclado a la operación de la resta, ligado a la muerte y gatillado por el cadáver de Ingrid, nos permite leer el texto desde nuestra segunda categoría, a saber: la clase social, la que es vista desde una perspectiva cultural amplia y vinculada con el habitus, es decir, como planteara Bourdieu (1979), el conjunto de orientaciones que son producto de la socialización primaria de los individuos, como la familia y la escuela, y que permiten explicar las prácticas culturales de las personas además de las diferenciaciones entre las mismas. En la obra, Paloma e Iquela forman parte de una burguesía que goza de un alto capital cultural, mientras que Felipe toma lugar dentro del complejo concepto de clase media. Esta última es difícil de diferenciar y produce un boundary problem vinculado con la construcción de los esquemas de clase, un conflicto inevitable si se tiene en cuenta que la clase es producto de una constitución histórica contingente, cuyo orden tiene bases políticas y su destino está siempre bajo amenaza (Gayo 373). Por otro lado, se le tiende a considerar un proyecto antes que una realidad, ubicados en una zona liminar entre los proyectos reivindicativos de los desposeídos y la hegemonía vigilante de los poderosos (Candina 14-15).

Acabamos de comentar la dualidad abierta por dos personajes que comparten el rol de narradores: la voz realista de Iquela y la figurativa de Felipe, identificable con una clase intelectual acomodada la primera y una más desventajada el segundo (su apellido Arrabal lo ubica en la periferia de la ciudad o incluso en los extramuros que colindan con el campo). En consonancia con tal organización de las perspectivas, será Iquela quien llevará la anécdota de la historia oficial y referencial, en tanto que Felipe transitará por el terreno de lo imaginado. Mientras ella está anclada a lo real, él permanece en el horizonte de lo posible. La tensión social que llega a existir entre estos dos personajes —radicalizada por el hecho de que el padre de uno delate al padre del otro-, si aceptamos una lectura de este tipo, será puesta de manifiesto por medio de una brillante estrategia alegórica: oponer lo liviano a lo pesado. El peso se conecta con el pasado y la ruina, pues guarda directa relación con aquellos muertos que tanto obsesionan a Felipe y que, por lo 
mismo, necesita restar. Él se rebela, en ese sentido, tanto a la liviandad y la "claridad" de Iquela como también a la de Paloma, la hija del exilio, quien además le resulta atrozmente ajena y alejada de su realidad local pese a ser chilena:

¿Cómo esos ojos van a querer atravesar la montaña para buscar una muerta?, cruzar y ver cenizas y en vez de tulipanes y algodones de azúcar, mal que mal la gente liviana ve cosas livianas y la Paloma pesa menos que un paquete de cabritas, si por algo le pusieron $\mathrm{Pa}$ loma, aunque en realidad le pudo tocar Victoria o Libertad o Fraternidad, la Frate, ¡creatividad pura!, no como en mi caso, que me tocó heredar con nombre y apellido, igual que los chistes, que repetidos salen podridos. (127)

Frente a la prepotencia de Paloma para que apuren el cruce por la cordillera, Felipe instala el resentimiento. A él se le murió su mamá de súbito, de un zuácate ${ }^{5}$, sin que pudiera ni intentar restarla. Por lo demás, es una muerte que se produce en plena dictadura y en manos de sus servicios de inteligencia, en un contexto de lucha social. La madre de Paloma parte al exilio y muere, en cambio, de cáncer: la enfermedad individualista propia del capitalismo tardío, según señala Susan Sontag en La enfermedad y sus metáforas (1977) ${ }^{6}$. Por otra parte, una de las diferencias más relevantes entre estos dos personajes y con mayores resonancias de sentido para la novela serán sus operaciones vitales: si Felipe resta, Iquela suma. Las listas mentales del espacio de Iquela tienden a llenarse en lugar de vaciarse:

5 "Zuácate" es un chilenismo que quiere decir repentinamente, de improviso, sin previo aviso.

6 Susan Sontag, cuando se refiere a la enfermedad y sus metáforas, específicamente al cáncer, entendido como un padecimiento vinculado a la represión y contención de las emociones, considera que los personajes de la novela americana del final de la Guerra Fría en adelante son perfectas víctimas de esta enfermedad: "El antihéroe pasivo, sin afectos, que domina la novela americana de hoy, es un ser de rutina metódica o de libertinaje insensible; no autodestructivo: prudente; no humano, ni impetuoso, ni cruel: sencillamente indiferente. Candidato ideal, según el mito de hoy, al cáncer" (51). Es una enfermedad que se asocia, de hecho, a un estadio avanzado del capitalismo que exige la especulación, la creación de nuevas necesidades (en el juego de la satisfacción/insatisfacción), la compra a crédito y la movilidad. Las imágenes del cáncer "resumen el comportamiento negativo del homo economicus del siglo XX: la imagen del crecimiento anómalo; la de la contención de la energía, es decir, la de negarse a todo consumo o gasto" (66). 
Resistí el silencio construyendo un listado mental de ese espacio, evitando así que la incomodidad se reflejara en mis ojos, siempre incapaces de disimular. Y conté doce maletas arrastradas por cuerpos exhaustos, un collar de perlas sosteniendo una papada, dos carteles de cartón con apellidos extranjeros y tres vuelos atrasados, suspendidos, cancelados. (44)

Felipe sostiene el remordimiento y llama burgueses a los muertos. Persiste en resistir la diferencia de clase incluso hacia el final de la novela, cuando el objetivo compartido de dar con el cadáver de Ingrid al fin se cumple:

un montón de cadáveres esperándome en sus casitas rectangulares: ya no en sus fosas en el suelo, ya no almacenados en cajas de servicios fríos y médicos y legales, no, ya no están echaditos en los paraderos y en los parques, ahora son bien burgueses los cadáveres y mejor así, claro, mejor tener muertos obedientes, preparados para cruzar en tropas la cordillera y que yo los reste por puñados. (253)

Son muertos guardados en sus féretros y no repartidos por la ciudad abandonados a su suerte. Son muertos clasificados y no hechos desaparecidos. En definitiva, son muertos con cuerpo y no fantasmas. Felipe se quiere apropiar de esa última muerta que es Ingrid: "la muerta genérica". Huye con su cuerpo y declara "esta muerta es mía y me la quieren quitar" (258), parodiando una canción folklórica del sur de Chile: El costillar es mío.

Si Felipe es el personaje que sostiene y da sentido al título de la novela, en tanto es el encargado de restar, el orden de los factores dispuestos sí alterará el producto. La suma no supone este problema. Existe una condena de clase que no es conmutable ni permite la movilidad social. Otro orden de cosas sería posible si la operación matemática de la novela fuera, por ejemplo, la multiplicación o la suma incontrolada y exponencial: aquella lógica del "chorreo" según la cual el crecimiento económico de los más poderosos llega a tener también beneficios para las clases más perjudicadas. Sin embargo, nuestra estructura económica, basada en el juego de suma cero de la guerra, donde para que unos ganen, otros deben perder —condición sine qua non para que el sistema funcione-, no permite un reparto justo y abundante de los recursos. 


\section{Conclusiones: la resta que suma de Alia Trabucco}

Pese a que, desde su título, la novela de Trabucco se propone restar, la voz de Felipe más bien tiende a atiborrar el plano de elementos en un acto algo compulsivo. Se recrea el porvenir imaginando y ampliando nuevos horizontes. La alucinación que experimentan los tres jóvenes hacia el final del relato, cuando beben un medicamento que le habrían recetado a la madre de Paloma como paliativo contra el cáncer, los transporta a un universo figural. Cuando Felipe retorna de su viaje “psicotrópico", confiesa: “abrí los ojos y mi impulso fue enumerarme, inventariarme, inventarme de nuevo" (226). La novela, de hecho, cierra con un pasaje casi místico de muerte y renacimiento enunciado por Felipe: "con mi voz que muere y renace debo gritar mientras me alumbro, mientras me nazco a mí mismo, mientras me engendran las llamas debo quemar el aire con mi voz, con mi último aullido, con mi cifra: menos uno, menos uno, menos uno" (279). Se resta incluso a sí mismo.

Cabe preguntarse cómo concluir una obra tan compleja como esta. Precisamente será a través del viaje alucinatorio que, según adelantamos, cumple un rol fundamental en la estructura dramática de la novela. Frente a la frustración provocada por las dificultades para poder dar con el cuerpo de Ingrid, los tres jóvenes deciden ir a emborracharse a un bar de Mendoza. Se tomarán aquel remedio que lleva Paloma consigo y que fue útil a su madre "para curar a las células confundidas, desencajadas" (223). Caen en un estado de alta percepción sensorial y de éxtasis donde los cuerpos - las bocas, las lenguas, los gestos - se ven indiferenciados. Lo que hay tras la vivencia es una aproximación hacia la nada. Es la droga la condición de posibilidad para saltarse la letra, que de un momento a otro deja de tener sentido, deja de ser leíble o interpretable ${ }^{7}$. Experimentan una elipsis o un olvido que les permite reescribirse o reinventarse, algo que solo

$7 \quad$ Cecilia Sánchez (2013) realiza un recorrido en torno al significado de la letra en la configuración de nuestra problemática modernidad latinoamericana. En la línea de Ángel Rama, la letra aludiría a una pretendida unidad entre el signo y la idea: "Dicha concordancia supone mantenerse en la proximidad de la voz de una conciencia racional (...). En cierto modo, esta es la forma en que se entiende la universalidad del discurso letrado, ya que mientras más próximo a la idea, más despojado de elementos y de estilos particulares se encuentra" (265-266). La escritura, en tanto, consiste en una resistencia a un trazo fijo. A contrapelo de las gramáticas del orden, surgen también estas discrepancias y fugas que más bien responden a retóricas de la pasión. Allí se alojan los restos del lenguaje. 
se vuelve posible una vez que se liberan de la mirada del otro - una pulsión escópica presente a lo largo de toda la novela-: "Me paré a su lado, y con el pulso galopando en mi pecho, con la boca reseca y las manos empuñadas, abrí los ojos (y mi impulso fue enumerarme, inventariarme, inventarme de nuevo). Pero no estaba. No había nadie devolviéndome la mirada" (226).

El mismo movimiento hacia la nada es experimentado por Felipe, quien se siente aliviado tras todo lo vivido y recupera una visión propia, no sobredeterminada por lo ajeno: "el planeta vibra porque no siento nada, ni el todo ni las partes, ni lo verdadero ni lo falso, no siento nada y estoy curado, sí, porque me curó el remedio de la gringa y por eso mis párpados son cortinas y por dentro se iluminan mis ideas negras" (229). Sin embargo, Trabucco no se acomoda en ese vacío anclado a un presente puro (la vivencia psicotrópica del instante) ni tampoco descree del pasado. Más bien asimila dicho pasado con la incomodidad y el sufrimiento que ello conlleva, y de esa forma moviliza una búsqueda que se recrea en determinados elementos alegóricos. Toda la experiencia fue como una gran resta: "Solo entonces noté lo que había pasado con mis manos. Seguían anestesiadas, perdidas en algún lejano rincón del bar (partes borrándose, restándose por pedazos)" (235). Con todo, se trata de una resta epicúrea, una resta que suma e imagina nuevas posibilidades de resignificar las experiencias. Se corresponde con esa persistencia y movimiento constante de las escritoras tránsfugas que, a partir de la desesperación, se lanzan en una búsqueda de nuevos significados con total arrojo.

En conclusión, Trabucco deja traslucir una dialéctica entre los personajes de Iquela y Felipe, quienes generan una comunión afectiva permanentemente tensionada por sus diferencias. La novela propone una inversión de los roles tradicionales del género y, al mismo tiempo, se permite representar a través de sus personajes protagónicos un conflicto de clase cuya disputa pasa alegóricamente por la figura de los muertos: el dolor que provoca la muerte y el pasado dictatorial. De tal forma, la autora decide situarse en el cruce o límite de dos mundos que, si bien pudieron haber estado motivados por una ideología común, poseen un universo de referencias distintos. Iquela y Paloma pertenecen a una clase media alta intelectual militante, mientras que Felipe, criado en Chinquihue con su abuela Elsa, se mueve más bien 
en los márgenes. En cualquiera de los dos casos, se ubican en un vacío que expresa la dificultad de procesar el dolor: una emoción que acabó siendo monopolizada por los mayores de edad, o bien, aquellos que experimentaron el dolor del exilio y de la muerte de los cercanos: la cicatriz de lado a lado de Rodolfo o la amargura y el olor a pena de Consuelo, padre y madre de Iquela respectivamente. La distancia que existe entre los dos niños es radicalizada con una vuelta a la democracia que persistió en un modelo económico neoliberal injusto y poco igualitario, no obstante, esos muertos del pasado y del presente son una carga para los tres jóvenes, quienes comparten el rol de integrarlos a un relato común pues, como el mismo Felipe señala: "En realidad, ¿qué importa de quién sean los muertos, no? El problema no es ese, dijo más convencido. Hay que ayudarse con los muertos; hay demasiados" (264).

\section{Referencias bibliográficas}

Amaro Castro, Lorena. "Formas de salir de casa, o cómo escapar del ogro: relatos de filiación en la literatura chilena reciente". $L i$ teratura y Lingüística, no. 29, 2014, pp. 96-109.

Ahmed, Sara. La política cultural de las emociones. México, D.F., Universidad Nacional Autónoma de México, 2015.

- La promesa de la felicidad. Una crítica cultural al imperativo de la alegría. Buenos Aires, Caja Negra, 2019.

Álvarez, Ignacio. "Sujeto y mundo material en la narrativa chilena del noventa y el dos mil: estoicos, escépticos y epicúreos". Revista Chilena de Literatura, no. 82, 2012, pp. 7-32. Recuperado de http://www.scielo.cl/scielo.php?script=sci_arttext\&pid $=$ S0718-22952012000200002. 12 agosto de 2019.

"Vuelven los padres: niños, historia y autoridad en la narrativa chilena reciente". Jornadas: En el país de nunca jamás. Narrativas de infancia en el Cono Sur, 2 y 3 de octubre de 2013. Pontificia Universidad Católica de Chile, Instituto de Estética. Santiago de Chile, PUC.

Braidotti, Rosi. Sujetos nómades. Corporización y diferencia sexual en la teoría feminista contemporánea. Buenos Aires, Paidós, 2000. Transposiciones: sobre la ética nómada. Barcelona, Gedisa, 2009.

Bourdieu, Pierre. La distinction. Paris, Les Éditions de Minuit, 1979. 
Butler, Judith. El género en disputa: el feminismo y la subversión de la identidad. 1990. Trad. María Antonia Muñoz. Barcelona, Paidós, 2007.

Candina, Azun. Por una vida digna y decorosa. Santiago de Chile, Esfera de Papel Libros/Facultad de Filosofía y Humanidades de la Universidad de Chile, 2009.

Costamagna, Alejandra. "Las nuevas rebeldías. Sobre La resta de Alia Trabucco Zerán”. Taller de Letras, no. 59, 2016, pp. 209-212.

Deleuze, Gilles y Félix Guattari. Kafka: por una literatura menor. 1975. Trad. Jorge Aguilar Mora. Buenos Aires, Ediciones Era, 2001.

Gayo, Modesto. "El problema de la delimitación o boundary problem. Una aproximación a la definición de la clase media". Revista Polis, vol. 12, no. 36, 2013, pp. 367-385.

Guerra, Lucía. Ciudad, género e imaginarios urbanos en la narrativa latinoamericana. Santiago de Chile, Cuarto Propio, 2014.

Hoggart, Richard. The uses of literacy: Aspects of working class life. Oxford, Oxford University Press, 1957.

Jeftanovic, Andrea. Hablan los hijos: discursos y estéticas de la perspectiva infantil en la literatura contemporánea. Santiago de Chile, Cuarto Propio, 2011.

Marchant, Patricio. Escritura y temblor. Eds. Pablo Oyarzún y Willy Thayer. Santiago de Chile, Cuarto Propio, 2000.

Meruane, Lina. Contra los hijos. México, D.F., Tumbona, 2015.

Moraña, Mabel e Ignacio Sánchez Prado. Eds. El lenguaje de las emociones. Afecto y cultura en América Latina. Madrid/Frankfurt, Iberoamericana Verbuert, 2012.

Ortega, Julio. Nuevos hispanismos: para una crítica del lenguaje dominante. Madrid/Frankfurt, Iberoamericana Verbuert, 2012.

Rodríguez Valentín, Ana Eva. "Reseña de La resta de Alia Trabucco". Revista Literatura y Lingüistica, no. 33, 2016, pp. 473-476.

Sánchez, Cecilia. El conflicto entre la letra y la escritura. Legalidades/ contralegalidades de la comunidad de la lengua en HispanoAmérica y América-Latina. Santiago de Chile, Fondo de Cultura Económica, 2013.

Sau, Victoria. "De la facultad de ver al derecho de mirar". Nuevas masculinidades. Eds. Marta Segarra y Àngels Carabí. Barcelona, Icaria, 2000, pp. 29-40. 
Paz Soldán, Edmundo. "Antígona en Santiago: La resta, de Alia Trabucco Zerán". Providinci. 25 de enero de 2016. Recuperado de http://prodavinci.com/2016/01/25/artes/antigona-en-santiago-la-resta-de-alia-trabucco-zeran-por-edmundo-pazsoldan/ 22 de mayo del 2017.

Sontag, Susan. La enfermedad y sus metáforas. 1977-1978. Trad. Mario Muchnik. Madrid, Taurus, 1996.

Ternicier, Constanza. "Los conflictos de una literatura nacional: raíces y desarraigos". Revista Hispamérica, vol. 47, no. 140, 2018, pp. 25-35.

Trabucco, Alia. La resta. Madrid, Demipage, 2015.

Viart, Dominique. "Le silence des pères au principe du 'récit de filiation"'. Études Françaises, vol. 3, no. 45. Figures de l'héritier dans le roman contemporain, 2009, pp. 95-112. 